American Journal of Environmental Sciences 4 (4): 297-302, 2008

ISSN 1553-345X

(C) 2008 Science Publications

\title{
Field Behavior of A High Anchored Reinforced Earth Wall
}

\author{
${ }^{1}$ Faisal Hj Ali, ${ }^{2}$ Bujang B.K. Huat and ${ }^{1}$ Lee Chee Hai \\ ${ }^{1}$ Department of Civil Engineering, University of Malaya, 50603 Kuala Lumpur, Malaysia \\ ${ }^{2}$ Department of Civil Engineering, University Putra Malaysia, 43400 UPM Serdang, Malaysia
}

\begin{abstract}
Since the invention of Reinforced Earth by the French architect Hendri Vidal in 1966, numerous reinforced soil walls have been designed and constructed all over the world. In this study the focus was on a particular type of reinforced wall called Nehemiah wall which differed from the Vidal type in the sense that instead of steel strips, the reinforcing elements consisted of steel bars with anchor blocks attached at the free ends. A full scale high anchored reinforced earth wall was constructed and instrumented to capture the essential behavior of the wall. Two sections of the wall were monitored where at one of the sections polystyrene foam was inserted at the back face of the wall panel to allow for lateral deformation to take place which means that the facing was less flexible in the transverse direction. The lateral deformation, axial forces along the reinforcing bars and settlement were monitored and measured for both cases and the results were compared and discussed.
\end{abstract}

Key words: Anchor blocks, instrumentation, lateral movement, reinforced earth, settlement

\section{INTRODUCTION}

When the reinforced earth system was first introduced by Henri Vidal, there was a large amount of research being poured into it in an attempt to understand its behavior and thereby able to establish a rationale basis of design. The research culminated in the publication of the French code of practice for reinforced earth in 1980 called "Reinforced Earth Structures-Recommendations and rules of the art". For the first time a rational basis of design using the coherent gravity method is explained in the code. The French code is followed by the design and construction guideline published by the Federal Highway Administration (FHA) in USA ${ }^{[1]}$. The FHA guideline is followed by the National Concrete Masonry Association design manual ${ }^{[2]}$ and the British Code (BS 8006:1995) ${ }^{[3]}$. Each successive code and design manual further refines the earlier codes. Despite the successive refinements in the design methodology or approach, the fundamental design philosophy remains the same that is, it is based on the limit equilibrium method. The basic design assumptions of all these codes and manuals are that the reinforced soil structure is sitting on a firm ground or piled foundation and that there is little yielding of the lateral boundary. In other words, the present design methodology is unable to take into account the effects of yielding at the base and as well as at the facing of the wall. Hence, if the wall is sitting on a compressible founding soil layer, the present design method is unable to capture the changes in the stresses in the reinforcing elements of the wall as a result of the yielding base boundary. Likewise, if the facing of the wall is allowed to move laterally, the present design method is again unable to capture the changes in the tensile stresses developed in the reinforcing elements due to the lateral yielding.

Therefore the main objective of the study was to investigate the effect of lateral yielding of the facing on the behavior of a full scale reinforced earth. An anchored reinforced earth called Nehemiah Wall was chosen and the instrumentation and monitoring works were carried at two sections of the wall where at one of them polystyrene foam was inserted at the back face of the wall panel to allow for lateral deformation to take place.

Nehemiah Wall: The Nehemiah anchored earth wall was first developed and introduced in Malaysia in 1993. The system has been used all over Malaysia and is now being implemented in countries like Singapore, India, Sri Lanka and Bangladesh. Majority of the applications of Nehemiah wall are found in infra-structural projects like highway interchanges, bridge abutments and highways going through mountainous terrain like KL-Karak highway and Second East-west highway. A detail description of the various applications of Nehemiah wall can be found in ${ }^{[4,5,6,7]}$. The case history of the design, construction and performance of a Nehemiah wall for a bridge over rail project in Malaysia is reported by Lee and $\mathrm{Oh}^{[8]}$. Lee and Nilaweera ${ }^{[9]}$ reported the construction of a $20.5 \mathrm{~m}$ high

Corresponding Author: Faisal Hj Ali, Department of Civil Engineering, University of Malaya, 50603 Kuala Lumpur, Malaysia 297 


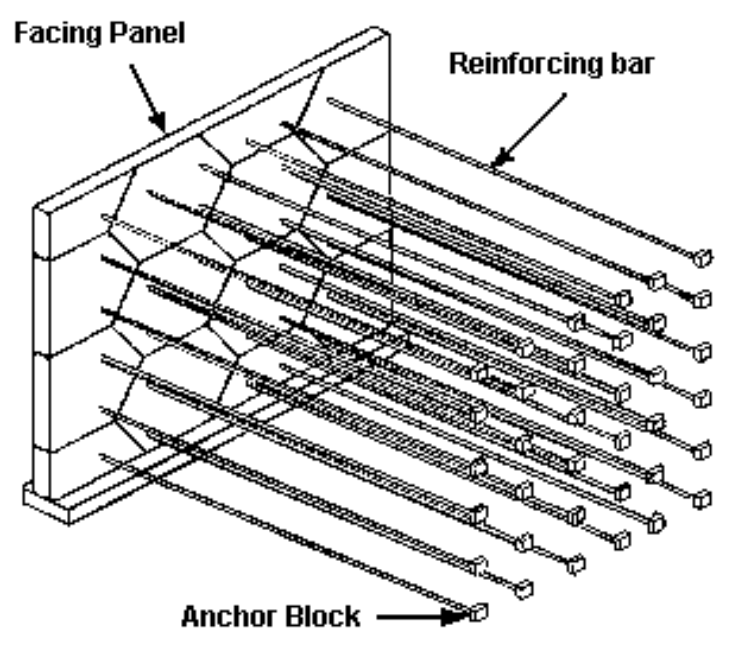

Fig. 1: Schematic representation of nememiah wall

Nehemiah wall in the Cameron Highlands. This is the highest Nehemiah wall built so far. A schematic representation of the Nehemiah wall is shown in Fig. 1.

The system is similar to the Vidal system except that the reinforcements consist of round steel bars with precast anchor blocks attached at the free ends of each of the reinforcing bars.

\section{CONSTRUCTION OF FULL SCALE WALL}

The full scale wall was designed according to BS $8006: 1995^{[3]}$. It was constructed as part of a development project and to support an access road. In view of the large height of the wall, it was broken into two tiers with the upper tier being offset from the lower tier by a distance of $1.5 \mathrm{~m}$. The subsoil consisted of an upper stratum of firm to stiff sandy clayey silt. Generally, the shear strength of the stratum increased with depth. The sandy clayey silt stratum was underlain by highly decomposed shale.

River sand was used as backfill material. Resistivity test was carried out and found to range from $12500 \mathrm{ohm} \mathrm{cm}$ to $14440 \mathrm{ohm} \mathrm{cm}$, which was considered as non-corrosive and suitable for use as backfill. The $\mathrm{pH}$ value of the sand was found to be 5.5. The resistivity and $\mathrm{pH}$ were measured to ensure that the backfill material was not corrosive. The shear strength parameters were obtained from shear box test. The angle of friction was found to be 42 degrees at peak stress while at residue stress the angle was 33 degrees. Conservatively, an angle of friction of 36 degree at peak stress was assumed in the design. The cohesion was taken to be zero.

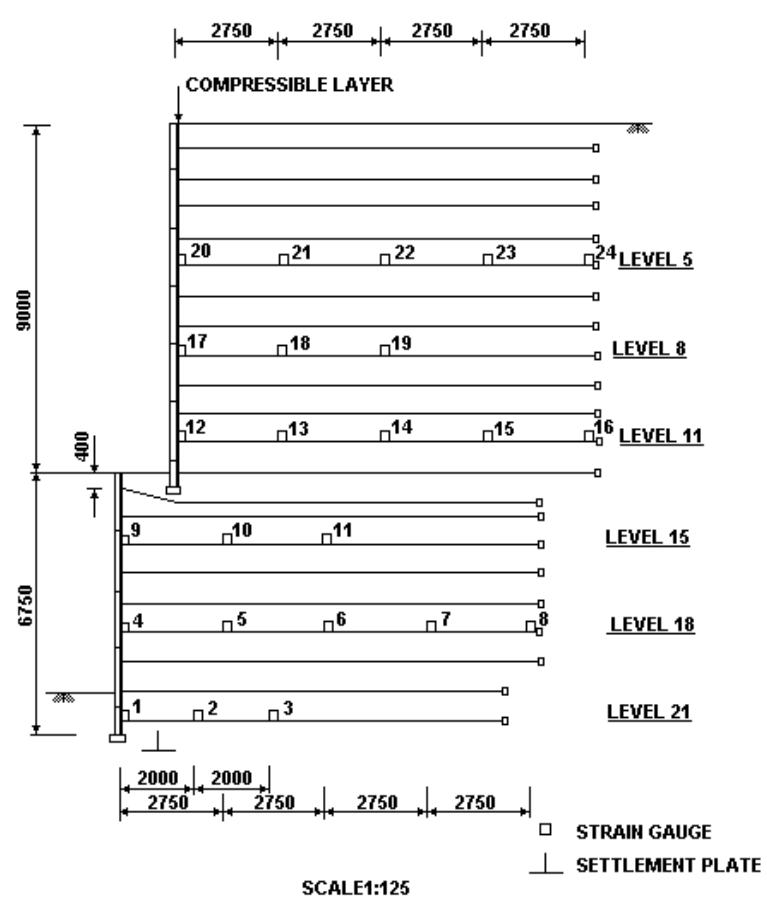

Fig. 2: Instrumented section of the wall (rigid facing)

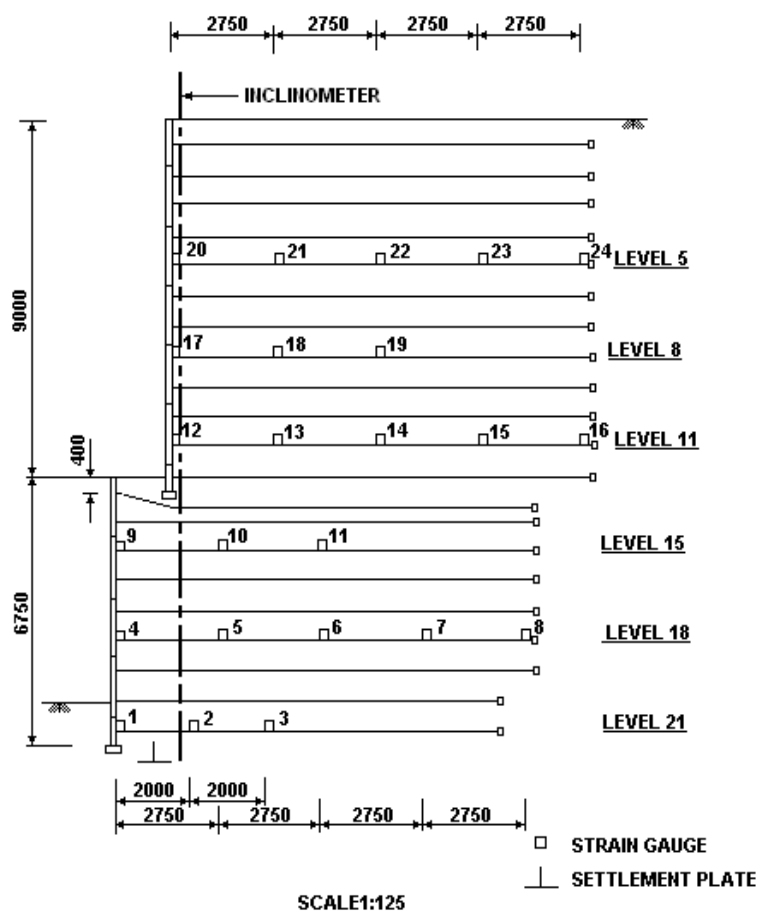

Fig. 3: Instrumented of the wall (flexible facing) 


\section{INSTRUMENTATION}

Two sections were selected for instrumentation. At one of the sections polystyrene foam was inserted at the back face of the wall panel to allow for lateral deformation to take place. At the other location there was no polystyrene foam insertion, which means that the facing was less flexible in the transverse direction. The instrumented sections are shown in Fig. 2 and 3. Basically, the instrumentation consisted of inclinometer, rod settlement gauge and load measurement along the reinforcing bars at selected levels.

\section{MEASURED RESULTS}

Rigid Facing: The tensile forces along the reinforcing bars were measured by resistance wire strain gauges. Fig. 4 shows the distribution of the tensile forces along the reinforcing bars at their respective levels. It was seen that the maximum tensions occurred at distance away from the facing. The locus of maximum tension was more or less a vertical line at $0.35 \mathrm{H}$ (where $\mathrm{H}$ is the overall height of the wall) offset from the back face of the wall facing. In a tie back system; the tensile force in the reinforcing bar was constant throughout the length of the bar. Hence, the variation of the tensile force along the reinforcing bar confirmed that Nehemiah wall was indeed a reinforced soil system rather than a tie back system.

The variation of the horizontal pressure with the normalized depth below the crest of wall is plotted and shown in Fig. 5. The $K_{a}$ line was drawn in the same plot for comparison. Assuming angle of friction of $36^{\circ}, \mathrm{K}_{\mathrm{a}}=$ 0.26 . Whereas by assuming an angle of friction of $30^{\circ}$, $\mathrm{K}_{\mathrm{a}}=0.33$. The $\mathrm{K}_{\mathrm{a}}=0.33$ line seemed to be a more realistic representation of the measured results. Based on $\mathrm{K}_{\mathrm{a}}=0.33$ line, it was seen that for normalized depth less than 0.4, the horizontal pressure was above the $K_{a}$ line. The explanation for the higher horizontal pressures at shallow depths was that they were induced by the locked in stresses due to compaction. For normalized depth greater than 0.7, the horizontal pressure was below the $\mathrm{K}_{\mathrm{a}}$ line. Between the normalize depths 0.4 and 0.7 , the horizontal pressures followed closely the $\mathrm{K}_{\mathrm{a}}$ line. The approximate parabolic shape of the pressure distribution indicated that perhaps the wall at the toe deformed significantly more thereby resulting in lower horizontal pressure.

The variation of coefficient of lateral pressure with depth is plotted as shown in Fig. 6. The $\mathrm{K}_{\mathrm{a}}=0.26$ and $\mathrm{K}_{\mathrm{a}}=0.33$ were plotted. The $\mathrm{K}_{\mathrm{a}}=0.33$ line selected for

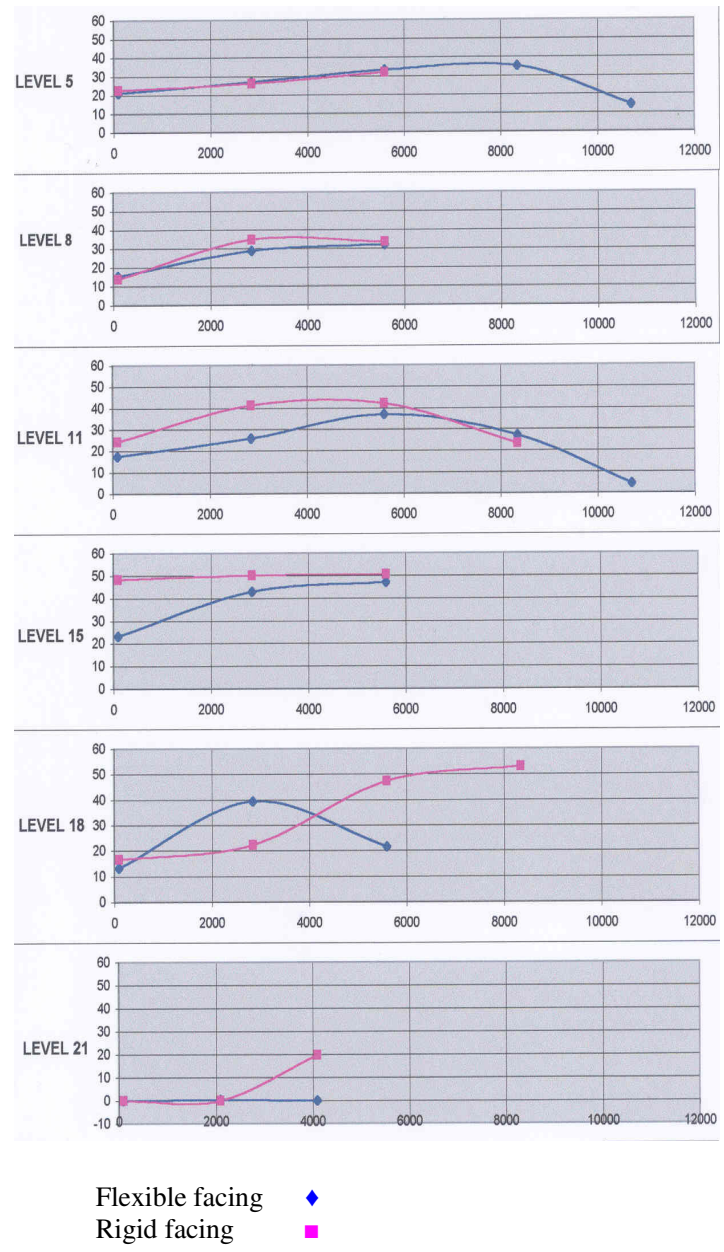

Fig. 4: Tensile force distribution along the reinforcing bars at both sections

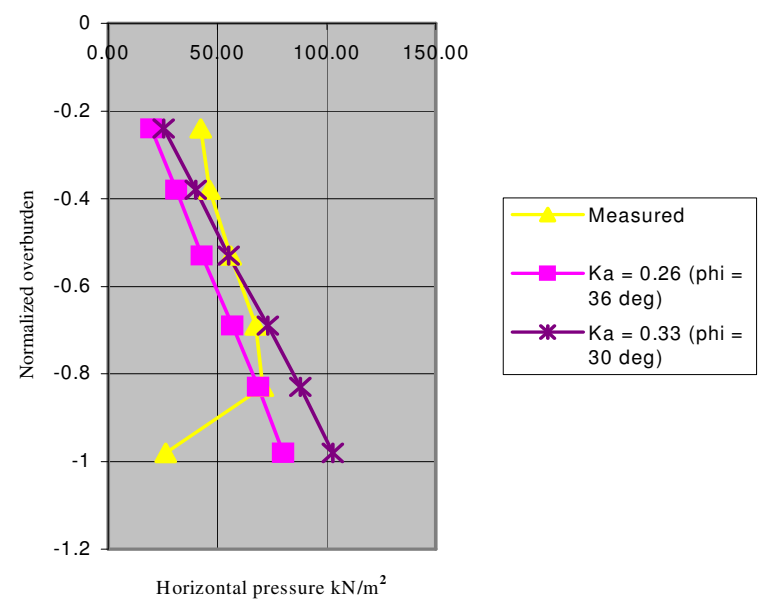

Fig. 5: Variation of horizontal pressure with overburden 


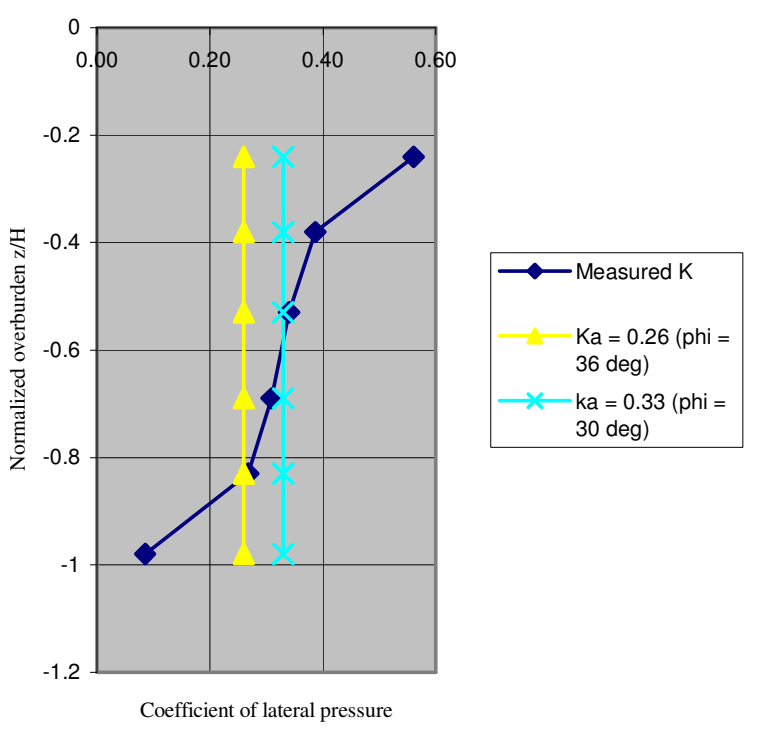

Fig. 6: Variation of coefficient of lateral earth pressure with depth of overburden

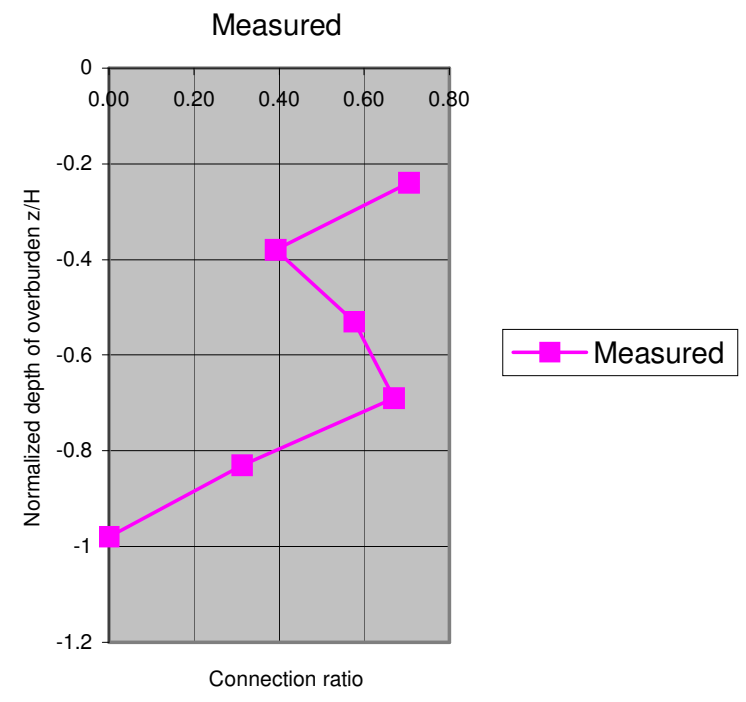

Fig. 7: Variation of connection ratio with depth of overburden

comparison. The coefficient of lateral pressure plot told a similar story as the horizontal pressure plot.

For shallow depths, that is $d_{n}$ less than 0.4 , the coefficient of lateral pressure far exceeded even the $K_{a}$ value. Whereas for deeper depth where $d_{n}$ was greater than 0.8 , the $\mathrm{K}$ value was far below the $\mathrm{K}_{\mathrm{a}}$ value. For $\mathrm{d}_{\mathrm{n}}$ between 0.4 and 0.8 , the $\mathrm{K}$ value was pretty well represented by $\mathrm{K}_{\mathrm{a}}$ value.

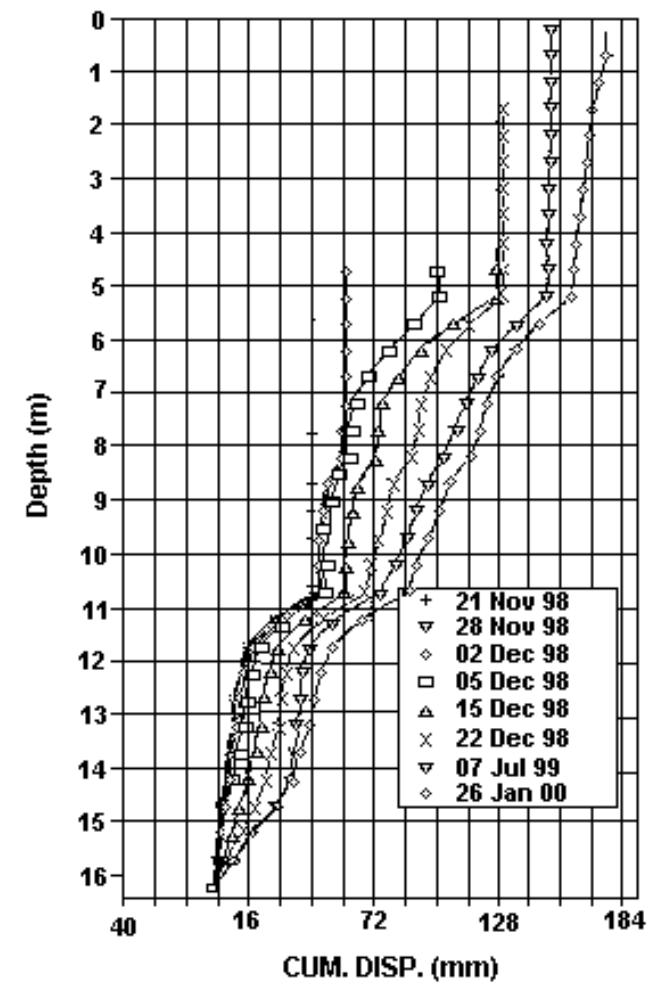

Fig. 8: Lateral displacement at wall facing

Connection ratio $(\mathrm{Cr})$ is an important parameter because the tensile strength of the reinforcing bar is generally the weakest at the connection. The connection ratio helps to determine whether the critical section is located at the connection or otherwise. The connection ratio is plotted against the normalized depth and shown in Fig. 7. It was seen that the $\mathrm{C}_{\mathrm{r}}$ fluctuated between 0.4 and 0.7 at shallow depths. When the overburden was larger than $0.7 \mathrm{H}$, the $\mathrm{Cr}$ decreased with depth till it reached zero at the toe of the wall. This is a significant departure from the behavior of Vidal (reinforced earth) wall where the connection ratio increases with depth till it is 1.0. A possible explanation for this phenomenon is that the wall facing at the lower part of the wall deforms significantly more than those measured in Vidal walls.

The lateral displacement in the backfill at the back face of the facing panels is measured by the inclinometer. The results are plotted as shown in Fig. 8. The results showed that the wall was tilting outward as it was erected incrementally. This wall movement brought about the Rankine active state of plastic equilibrium.

Flexible Facing: This was another section of the wall chosen for instrumentation. The geometrical 


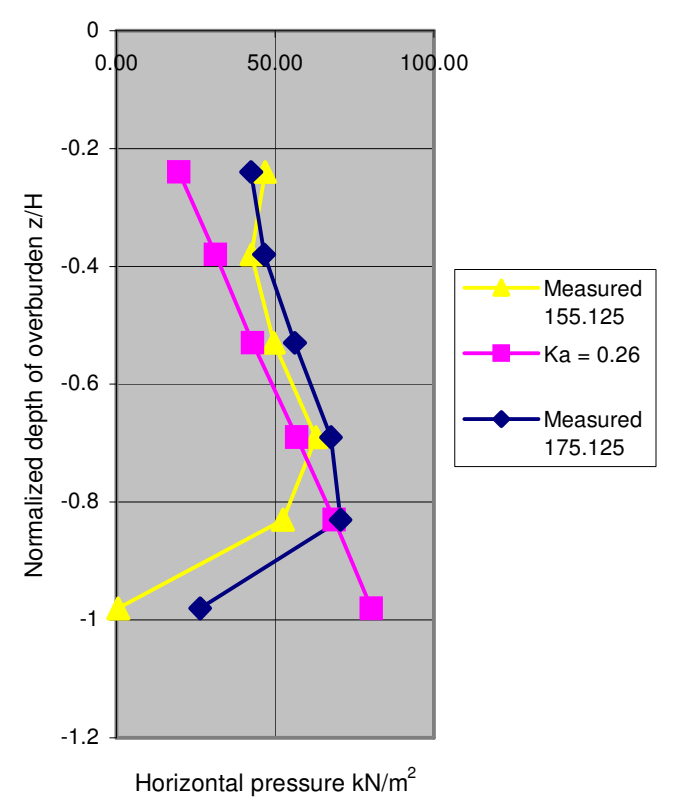

Fig. 9: Variation of horizontal pressure with depth of overburden

dimensions and design of the wall were similar to the rigid wall facing. The only difference was that at this section a layer of compressible geoinclusion made of polystyrene material was inserted at the back face of the wall to allow lateral deformation to take place. The purpose of introducing the compressible layer was to study the effect of yielding lateral boundary condition. The tensile forces were measured by the strain gauges. The tensile force distribution along the reinforcing bars at each of the instrumented level was shown in Fig. 3. For the purpose of comparison, the tensile force distribution was superimposed on the tensile force distribution of the rigid facing. It was seen that the trend of the locus of maximum tension in both sections was similar; that is the locus was a vertical line offset approximately $0.35 \mathrm{H}$ away from the facing.

The horizontal pressure is plotted against normalized depth (see Fig. 9). The horizontal pressure increased with depth until $d_{n}$ reached 0.7 whereby the horizontal pressure started to decrease with greater depth. It was seen that the curve for the flexible facing followed similar trend as the curve for the rigid facing except that the horizontal pressure at the flexible facing was generally slightly lower.

The variation of coefficient of lateral pressure with overburden for the flexible facing is shown in Fig. 10. It was seen that at shallow depths, the coefficient was much higher than $\mathrm{K}_{\mathrm{a}}$. Then as the depth increased, the

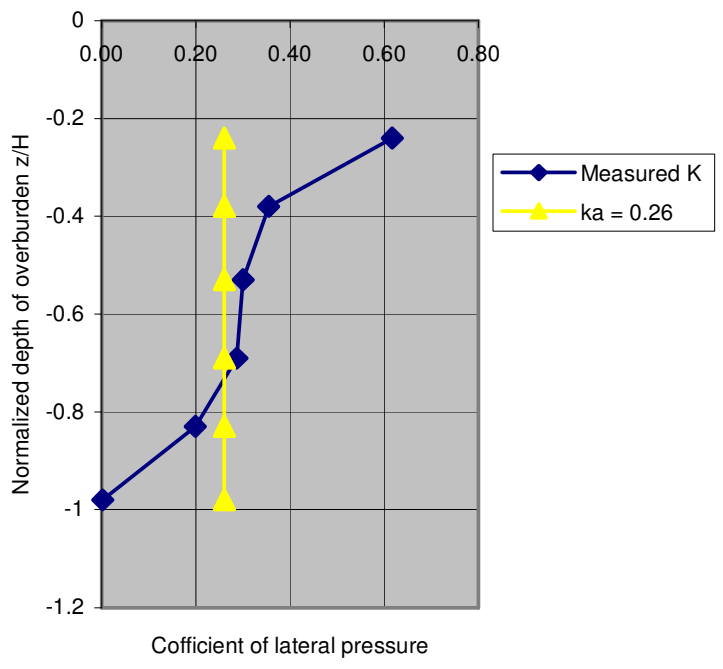

Fig. 10: Variation of coefficient of lateral pressure with depth of overburden

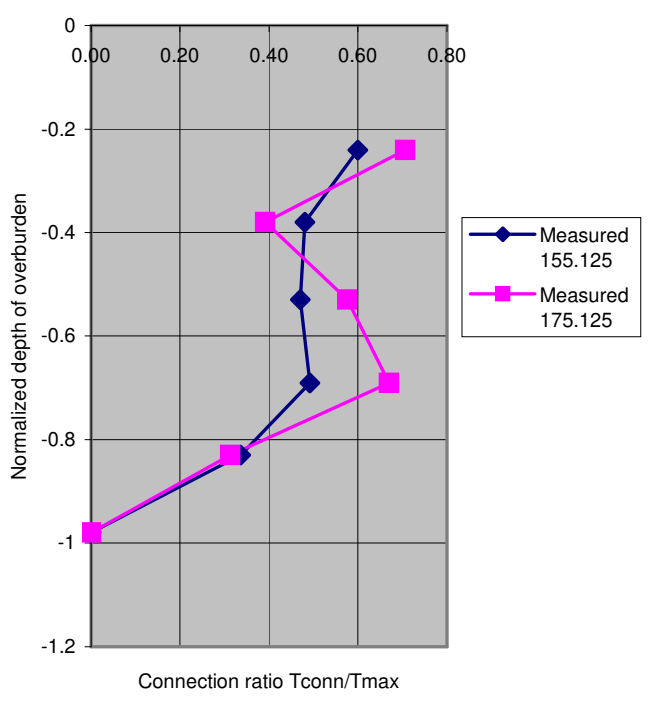

Fig. 11: Variation of connection ratio with depth of overburden

coefficient followed more or less the $\mathrm{K}_{\mathrm{a}}$ line. Below an overburden depth of 0.7 , the coefficient felt below the $\mathrm{K}_{\mathrm{a}}$ value.

The connection ratio $(\mathrm{Cr})$ of the flexible facing is plotted against the normalized depth (Fig. 11). The maximum value of $\mathrm{C}_{\mathrm{r}}$ was 0.6 and maintained more or less a constant value of approximately 0.48 for depth between 0.38 and 0.69 . Then the $C_{r}$ value dropped rapidly to zero toward the base of the wall. The connection ratios at the rigid facing were also plotted in 
Fig. 11. The connection ratio at rigid facing was generally higher than the connection ratio at the flexible facing.

\section{CONCLUSIONS}

A high anchored reinforced earth wall is fully instrumented to monitor the behavior during and after construction. The focus is on the difference in behavior between rigid and flexible wall. One of the walls is made less rigid by inserting compressible geoinclusion made of polystyrene material at the back face of the wall to allow lateral deformation to take place. The parameters measured include stresses along the reinforcement, lateral pressure in the backfill, and lateral deflection of the wall. Based on the observations made it can be concluded that, the trend of the locus of maximum tension in both sections is similar; that is the locus is a vertical line offset approximately $0.35 \mathrm{H}$ away from the facing. For lateral pressure, it is seen that the curve for the flexible facing follows similar trend as the curve for the rigid facing except that the horizontal pressure at the flexible facing is generally slightly lower. Lastly, the connection ratio at rigid facing is generally higher than the connection ratio at the flexible facing.

\section{REFERENCES}

1. Christopher, B.R., S.A. Gill, J.P. Giroud, I. Juran, J.K. Mitchell, F. Schlosser and J. Dunnicliff, 1989. Reinforced Soil Structures. Vol. I. Design and Construction Guidelines.
2. Simac, M.R., R. J. Bathurst, R.R. Berg and S. E. Lothspeich. 1993. Design Manual for Segmental Retaining Walls (Modular Concrete Block Retaining Wall Systems), $1^{\text {st }}$ Edition, National Concrete Masonry Association.

3. BS 8006: 1995. Code of Practice For Strengthened /Reinforced Soils and Other Fills.

4. Lee, C.H., 2001. Applications of Nehemiah AE walls. Master Builders Journal. First Quarter. pp: 25-27.

5. Ali, F., 2003. Factual report on pull out test for Nehemiah Anchored Earth wall. University Malaya, Kuala Lumpur.

6. Lee, C.H., 2000. Design and construction of a 9.6 $\mathrm{m}$ high segmental wall. Proceedings of the $2^{\text {nd }}$ Asian Geosynthetics Conference, Kuala Lumpur, Malaysia, pp: 19-24.

7. Ali, F., 1990. Field behavior of a reinforced earth wall in Malaysian conditions. Performance of reinforced soil structures. British Geotechnical Society. Pp: 169-173.

8. Lee, C. H. and Y.C. Oh, 1997. Design, construction and performance of an anchored earth wall in Malaysia. Proceedings of the International Symposium on Mechanically Stabilized backfill. Denver, Colorado, USA, pp: 185-192.

9. Lee, C.H. and N.S. Nilaweera, 2002. Design and construction of a $20.5 \mathrm{~m}$ high innovative Nehemiah wall near Cameron Highland, Pahang. Second World Engineering Congress, Sarawak, Malaysia. pp: 117-120. 